\title{
NOTE ON S-NUMBERS
}

\section{W. J. LEVEQUE}

The transcendental number $\xi$ is said to be an $S$-number if there is a $\gamma>0$ and a sequence of positive constants $\Gamma_{1}, \Gamma_{2}, \cdots$ such that for each polynomial $a_{0}+\cdots+a_{m} x^{m}$ of arbitrary degree $m$, with rational integral coefficients such that $a=\max \left(\left|a_{0}\right|, \cdots,\left|a_{m}\right|\right) \geqq 1$, the inequality

$$
\left|a_{0}+a_{1} \xi+\cdots+a_{m} \xi^{m}\right| \geqq \Gamma_{m} a^{-\gamma m}
$$

holds. It is well known (cf. $[1$, p. 63]) that if $\xi$ is an $S$-number, then $\gamma \geqq 1 / \sigma$, where

$$
\sigma=\left\{\begin{array}{l}
1 \text { if } \xi \text { is real, } \\
2 \text { if } \xi \text { is not real, }
\end{array}\right.
$$

and Khintchine [2] has shown that the measure of all real $S$-numbers with $\gamma=1$ is zero. On the other hand, Mahler [3] proved that almost all (real or complex) numbers are $S$-numbers. His proof shows that this statement is true with $\gamma=4$, and he conjectured that for almost all real numbers one can take $\gamma=1+\epsilon$, and that for almost all complex numbers one can take $\gamma=1 / 2+\epsilon$, for arbitrary $\epsilon>0$.

Let $\gamma_{r}$ be the infimum of all numbers $\gamma^{\prime}$ such that almost all real numbers are $S$-numbers with $\gamma \leqq \gamma^{\prime}$, and define $\gamma_{c}$ analogously in the complex case; thus Mahler's conjecture is that $\gamma_{r}=1, \gamma_{c}=1 / 2$. Koksma [4] showed that $\gamma_{r} \leqq 3$ and $\gamma_{c} \leqq 5 / 2$. Kubilyus [5] considered the special case $m=2$, and showed that then (1) holds for almost all $\xi$ if $\gamma>1 / \sigma$; i.e., he proved the conjecture for $m=2$. (It is well known for $m=1$.) By combining a theorem due to Fel'dman [6] with Mahler's original argument, it is shown here that $\gamma_{r} \leqq 2, \gamma_{c} \leqq 3 / 2$.

Lemma 5 of $\mathrm{Fel}^{\prime} \mathrm{dman}$ 's paper is as follows: Let $f(z)=a_{0}+\ldots$ $+a_{m} z^{m}$, where $a_{0}, \cdots, a_{m}$ are rational integers with $\left|a_{i}\right| \leqq a$, let $\xi_{1}, \cdots, \xi_{m}$ be its zeros, which are supposed distinct, and let $\zeta$ be an arbitrary complex number. If $\delta=\min _{i}\left(\left|\zeta-\xi_{i}\right|\right)$, then

$$
|f(\zeta)| \geqq \delta e^{-2 m^{2}} a^{-m}
$$

First consider the real case. If $f$ satisfies the conditions of Fel'dman's lemma and

$$
|f(x)| \leqq \mu a^{-2 m-3}
$$

Presented to the Society, September 5, 1952; received by the editors April 18, 1952. 
then

$$
\delta \leqq \mu e^{2 m^{2}} a^{-m-3} .
$$

Thus we have the following analogue of Lemma 2 of [3]: The point set $M(f)$ on the real axis, in which the polynomial $f(x)$ satisfies the inequality (2), has total length at most

$$
2 m \mu e^{2 m^{2}} a^{-m-3} \text {. }
$$

The remaining argument of [3] can be applied almost unchanged to this variant of Lemma 2 , and the inequality $\gamma_{r} \leqq 2$ results. (This constant 2 is the coefficient of $m$ in (2).)

In the complex case, if

$$
|f(z)| \leqq \mu a^{-3(m+1) / 2},
$$

then

$$
\delta \leqq \mu e^{2 m^{2}} a^{-(m+3) / 2},
$$

and so $z$ must lie in a set composed of at most $m$ circular regions, of total area at most

$$
\pi m \mu^{2} e^{4 m^{2} a^{-m-3},}
$$

and Mahler's argument leads to the inequality $\gamma_{c} \leqq 3 / 2$.

\section{BIBLIOGRAPHY}

1. J. F. Koksma, Diophantische Approximationen, Berlin, 1936.

2. A. Khintchine, Zwei Bemerkungen zu einer Arbeit von Herrn Perron, Math. Zeit. vol. 22 (1925) pp. 274-284.

3. K. Mahler, Über das Mass der Menge aller S-Zahlen, Math. Ann. vol. 106 (1932) pp. 131-139.

4. J. F. Koksma, Über die Mahlersche Klasseneinteilung der transzendenten Zahlen und die Approximation Komplexer Zahlen durch algebraische Zahlen, Monatshefte für Mathematik und Physik vol. 48 (1939) pp. 176-189.

5. I. Kubilyus; On the application of $I$. M. Vinogradoff's method to the solution of a problem in the metric theory of numbers, Doklady Akad. Nauk SSSR. N.S. vol. 67 (1949) pp. 783-786.

6. N. I. Fel'dman, The approximation of certain transcendental numbers, I, Izvestia Akad. Nauk SSSR. Ser. Math. vol. 15 (1951) pp. 53-74.

UNIVERSITY OF MANCHESTER 